\title{
Thermal Sprayed Composite Coatings for Biomedical Implants: A Brief Review
}

\section{Gaurav Prashar · Hitesh Vasudev}

School of Mechanical Engineering, Lovely Professional University, Phagwara-1444111, India.

ABSTRACT
The implant materials used currently in field of cardiovascular and orthopedics surgery dearth in
osteoconductivity. Different surface modification techniques are used, developed and investigated over the
years to enhance the osteoconductivity of biomaterials like metals, polymer and ceramics. Although
implants made up of metals are strong mechanically but have low bonding ability due to bio-inert nature.
To overcome the limitations and to accomplish the desired purpose, composite coatings consisting of
bioactive are developed on the metallic biomaterials. In general bio-inert ceramics like yttria stabilized
zirconia (ysz), titania, and alumina may be incorporated into hydroxyapatite (HA) matrix to develop
composite coatings with improved mechanical properties over the years. The composite coatings
developed by thermal spraying have shown promising approach to have good mechanical and biological
properties in comparison with single-component and/or monolayer coatings. The strategy to use
composite coatings is adopted widely by the professionals/scientists in the area of biomaterials for
development and production of materials in order to repair and regeneration of the human tissue. In this
article, commercially used thermal spraying techniques used for deposition of composite coatings for
biomedical implants are discussed.
(CIndian Thermal Spray Society and INScienceIN.2020. All rights reserved

ARTICLE HISTORY

Received 13-10-2020

Revised 26-10-2020

Accepted 27-10-2020

Published 11-12-2020

\section{KEYWORDS}

HVOF,

Plasma Spray

Ha Composite Coatings

Implants

Bio-Ceramics

\section{Introduction}

In the last few decades, owning to population aging and adaptation of modern lifestyle by human beings, millions of person has been gripped by the diseases like orthopedic, and maxillofacial [1]. Hence, solving these problems is the need of hour so that the human beings live a healthy and long life. As a result medical implants were in the demand as the implant technology is maturing day after day [2]. Scientists/researchers have already predicted that in near future more persons will be plagued by orthopedic diseases and associated economic burdens will rise at a rapid pace annually [3]. Aided by advancements in area of medical and biological sciences, metallurgy and materials science has succeeded in past years by discovering different materials for implant to repair human body tissues for number of people all around the globe. Currently, materials like metals, polymers, and ceramics are being preferred clinically for the implants and in various dental and medical fields [4-5]. Although these materials have served their objectives better, but some of the presently employed materials for implants has certain limitations in the biological environment. For instance one limitation associated with metallic biomaterials is the bioinertness like traditional orthopedic metals of SS and Cobalt-Chromium alloys, which leads to the development of fibrous tissues onto the implants of these metallic materials when implanted into the body of patient [5]. Owing to unique properties of alloys like Ti (titanium), Ti$6 \mathrm{Al}-4 \mathrm{~V}$, \& NiTi shape emory alloy are adopted for implant purpose in the orthopaedics, and dentistry related surgeries, etc [6-7]. But, the bioinertness is the shortcoming of these alloys and, also in $\mathrm{NiTi}$, the release of $\mathrm{Ni}$ ions to nearby tissues which are cytotoxic [8], have restricted their applications in medical field during longduration implantation.

The ceramics were not given a serious thought as usable biomaterials until the year 1970s. In last four decades, bioceramics, like ceramics, glass-ceramics, and glasses are intensively investigated and used for the repair of human hard tissues [9-11]. Bioceramics like bioinert $\mathrm{Al}$ and toughened ceramics (Zr) are being used in the implants for joint of hip. Since early 1980s, vast research and development activities has been carried out on some bioactive bioceramics like hydroxyapatite (HA), bioglass, and glass-ceramic [A-W] [12-14] due to chemical bonding of these materials with patients bone after the implantation. Nevertheless, most of the bioactive bioceramics for instance $\mathrm{HA}$ are not so strong and therefore can't be employed for the applications including load-bearing in body of human beings.

Nature develops the excellent designs and produces better materials. The tissues in body of the humans are the natural nanocomposite materials. Human bone, for instance, is a natural composite material having hierarchical structure with two stages of composite structure. Using bone as a template in early 1980s, Bonfield et al., [15] are the first to apply research onto bioceramicpolymer composites and found that bioceramic-polymer composites will be reliable for replacement and regeneration of hard tissue. Since then, number of bioceramic-polymer composites having different features have been developed and investigated to meet the different clinical requirements. To overcome the limitations of constituent materials, and tailoring the properties of composite materials through better composite design, over past three decades, new biomaterials are being developed through the composite approach and has gained wide acceptance in research \& development of biomaterials. The 
composite approach can be used for modification of surfaces of the metallic implants by developing composite coatings onto the metallic surfaces, resulting in enhancement of their properties and osteoconductivity. Composite coatings in comparison to monolayer coatings offer various advantages. This chapter discusses various thermal spraying techniques used for deposition of composite coatings for biomedical implants.

\section{Thermal spraying techniques used in modification of surfaces in case of biomaterials}

The conditions for depositing coatings on metallic implants have:

- no tailoring in the structure \& final composition of the developed bioceramic coating (vice versa if changes occurs during development of coating, then coating is not bioactive),

- better adhesion strength among the coating and metal implant,

- no reduction in strength of the implant after formulation of coating, and

- if possible, coating process will be economical, and process selected will be appropriate for the mass production.

At best few coating technologies can fulfill aforementioned requirements. However, the actual employability of a specific coating technique relies sometimes on grounds, that can be among the particular technology itself and various other factors (non-technical). High-velocity oxyfuel (HVOF) process and plasma technique are commonly used for developing bioactive bioceramic coatings onto the metallic substrates.

\section{HVOF spraying}

In thermal spraying process, the HVOF has gained wide attention in the research community for depositing bioactive bioceramic coatings. HVOF is a technique in which either gas or liquid fuels (e.g. Propylene, propane, hydrogen and kerosene) along with pure $\mathrm{O}_{2}$ are used for producing a high-speed flame. The process working principle and other details can be found in authors another publication [16]. Due to the higher particle velocity thick, and well-bonded coatings with lower amounts of oxides are produced by employing the HVOF technique. The high particle velocity associated with HOVF process resulted in a reducing the particles flight duration time. Thus, the particles have limited time for the oxidation reaction to occur. This elucidate that the coatings deposited by the HVOF technique have caused lower amounts of oxides in it [17-18]. Further, the HVOF produces high density coatings having a smoother surface finish with no interconnected porosity. Hence, the HOVF process has been widely used as corrosion protection coatings in many industrial applications.

In recent years, biocompatible coatings were also developed by HVOF. The HVOF technique offers distinctive advantages for the development of the biocompatible coatings as the working temperatures in the technique do not favor for the secondary phase precipitation in the material sprayed. Hydroxyapatite (HA) coatings were developed in the past few years by utilizing HVOF technique [19]. Even though at present there is no affirmation that HA coatings deposited by HVOF are available commercially, however studies [20-22] have advocated their edge after the in-vitro tests that affirm HVOF coatings can be soon used for commercialized purpose in biomedical industry. For example, the HA based coating formulated by the HVOF technique onto a customized hip prosthesis formulated by the process of metal additive manufacturing. This particular type of application is regarded to be as functional as the deposited coating must provide different properties to the substrate material. In case of prothesis, material of the coating provides with biocompatibility, and bioactivity. Addition to this when implanted in patient body it will also act as a passive barrier to restrict dissolution of metal ion.

In recent years, nanostructured coatings has gained wide attention due to improved mechanical properties [24-25]. Nano-sized ceramics like aluminium and titanium oxide possess good potential of improving osteoblast bonding on them [26]. Therefore, nano-scale particles within the biocompatible coatings could yield positive results. The nanostructured $\mathrm{Ti}+\mathrm{HA}$ composite coatings sprayed by HVOF may become a captivating solution for practical applications related to biomedical owning to the combined effect of a excellent mechanical performance as well as resistant nanostructured $\mathrm{TiO} 2$ stable phase, and also bioactive phase of HA, that can improve the performance of deposited coating [27]. Furthermore, heat treatment (HT) of HA composite coatings also yield positive results. HT of HVOF sprayed HA/ nano-Zr composite coating at temperature $750^{\circ} \mathrm{C}$ and duration $30 \mathrm{~min}$ enhanced the coating homogeneity by equalizing of the phase compositions \& achieving uniform value of Young's modulus in entire coating [28].

For developing long duration, stable biomedical coatings with better mechanical resistance focus shifted to HAp and HAp/TiO2 functional graded coatings developed by HVOF spraying. This novel approach allowed comparing the advantages of a multilayered coating architecture in relation to a commonly used single layer coating with practical application in biomedical. Authors recommended that by using such approach the quality coating microstructure was obtained efficaciously [29].

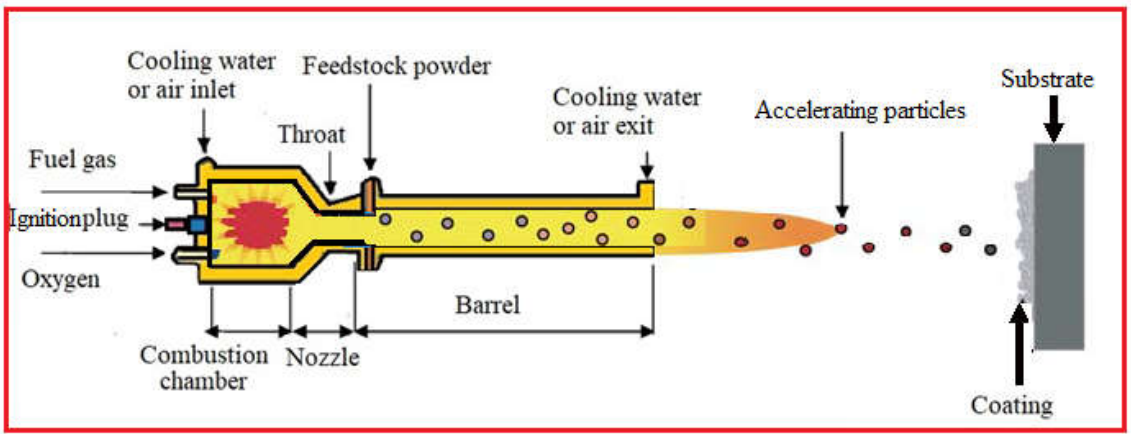

Figure1: Simplified diagram of the HVOF process 


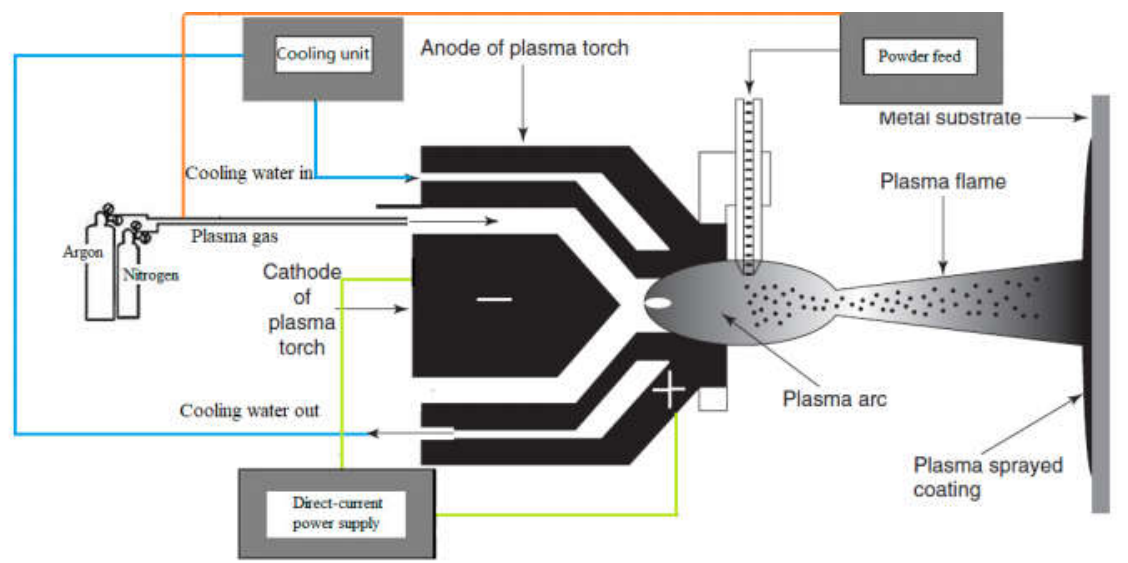

Figure 2: Simplified set-up of plasma spray technique

\section{Plasma spraying}

Plasma spraying turn-up in early 1980's as a preferred method to develop bioceramic coatings onto the metal components [30] and soon become choice of the industry's for formulation of HA coating for the hip prostheses [31] Plasma spraying is a member of thermal spray group that uses a high energy source of heat in order to melt and propel fine particles towards the prepared surface of component [32]. Upon impact with component surface, these molten particles so called 'droplets' starts to cool down and then solidify immediately by a heat transfer phenomena to the underlying component and hence formulate, by accumulation, a strong coating consisting of the lamellae structure.

For plasma spraying method, creation and use of plasma jet as the source of high temperature are realized in the spray torch of plasma [33]. As shown in a simplified manner in Fig. 2, the torch of plasma is made up of a thoriated cathode having cone-shaped (tungsten) geometry and anode (copper) of cylindrical shape. Gases (for generation of plasma) will flow across the space among the two electrodes and by utilizing high-frequency discharge an arc is initiated. The gas stream which flows among two electrodes will stretch the arc, and as a result the arc comes out of the torch nozzle as a plasma flame.

Argon, helium, hydrogen and nitrogen are used primarily as arc gases. The temperature of plasma flame is normally in range of $10000-15000{ }^{\circ} \mathrm{C}$. Consequently, in basics, almost any material (metal or ceramics including refractory materials or even oxides) can be melted to develop a coating by using plasma spraying. During the spraying process, feedstock materials (may be powder, wire, or rod) are exposed into the high temperature plasma flame for melting. The melted materials are then propelled towards the surface of substrate by plasma jet resulting in the formulation of hard coating with lamellae structure which corresponds to the typical characteristics of this process. (Figure 3). The final velocity and powder particles temperature are related directly to the type of plasma gas. Mostly the powders utilized for spraying have particle size in the range of $10-100 \mu \mathrm{m}$ in diameter to get desired acceleration and uniform heating. A constant powder feed rate (PFR) is a main requirement in order to get uniform thickness of coating with good quality. The feedstock powders also possess better flow properties, which is again related with powder morphology ie. shape and size. The coating developed by plasma method consists of the layered structures. The process parameter optimization in plasma spraying is difficult and costly task due to large number of operating parameters involved along with complex relationships which will exist between these parameters. However, due to nature of the plasma technique, there exist severe drawbacks also: (a) decomposition of bioceramic as a result of high temperatures involved in plasma spraying; (b) high percentage of thermal residual stresses in as-sprayed coatings; and (c) existence of defects like unmelted particles, pores, voids and cracks. The presence of pores will degrade the quality of the coatings, if operating parameters during spraying are not optimized. In contrast to the above mentioned discussion, extensive studies have also been conducted by numerous groups of researchers/professionals on utilizing the plasma spraying process to develop bioceramic coatings. There exists large body of technical literature on the spraying of monolayer bioceramic coatings by plasma method [13-14]. The final coating thickness of HA coatings developed by plasma sprayed will normally lies in the range from 50 to $200 \mu \mathrm{m}$. Hence it is feasible to utilize plasma spraying technique to develop multi-layered functional graded coatings (FGCs) on implants.

Currently, with the recent advancements in the usage of coating consisting of titanium devices, ceramic coatings sprayed by plasma method not only get most of the mechanical requirements, but also assist in providing appropriate environment for growth of tissues and bone cells [34]. It was recommended that ceramic coatings sprayed by plasma method are good enough to enhance mechanical properties along with wear and corrosion performance. There is no question mark that the improved performance of bioceramic coating is related mainly to better thermal stability, dense microstructure, and as well as chemical composition [35-37]. In addition to the good composition design of the coatings, suitable heat treatment might alter the mechanical properties [38].

In field of biomedical implants plasma sprayed HA coatings, appear to be the commonly used coatings for surface modification, as HA result in better biocompatibility and regeneration of bone among the tissue of bone and surface of implant [39]. The prime advantages of this method to develop 'HA' coatings can include better adhesion strength among the 'HA' coating and component. However, due to brittle nature of HA it becomes weak ceramic. Therefore, tough bioinert bioceramics like titanium oxide, aluminium oxide and zirconium oxide can be combining with HA to develop composite coatings. To enhance the long-duration biological stability of metallic implants coated by HA; Yang et al., [40] concluded that pure titanium used in industry 
can be employed as a fruitful bonding agent to remarkably enhance the interface bonding strength and to decrease stress of HA coating and titanium-alloy system. The exceptional bonding can be noticed among commercially available pure Ti and the component, and moreover surface roughness is also observed to be unchanged after the application of HA coating. Moreover, the resistance to corrosion and cytocompatibility were improved by HA and pure titanium plasma sprayed coatings on titanium alloy matrix [41]. An innovative bi-layer of HA/Al2O3-SiO2 nanocomposite coating in another study is developed on the titanium implants surface by plasma spray process. The results affirmed that double-layered nanocomposite plasma sprayed coating improves roughness, and other properties like wettability, cell viability, and proliferation in comparison with single layered strucutre of the HA coating [42]. Meantime, biofunctional coatings ( $\mathrm{Mg}, \mathrm{Sr}$ )-HA with greater bond strength were efficiently deposited by utilizing plasma-spray method [43]. Authors observed cellular extensions as well as extracellular matrices also secreted, which exemplify that composite coating consisting of $\mathrm{HA}$ with ions of $\mathrm{Mg}$ and $\mathrm{Sr}$ have excellent biological activity. Several issues in recent years have been takeup on stress shielding, bad osseointegration, difficulty in controlling the composition, poor porosity, as well as low bonding strength of the as-sprayed coating is an massive challenge, which effects the long-duration stability of metal implants. To further enhance the surface properties of metal implants, it is must to combine distinct surface modification methods to develop biofunctional coatings with exceptional multi-dimensional properties. In relation to this Ke et al., [44] observed, a gradient establish HA composite coating with excellent antibacterial properties was developed using plasma and laser spray technology for improving the mechanical properties.

\section{Various testing approaches that can be applied to biomedical implants}

Biocompatibility testing is performed to know the potential toxicity that results from the contact of the device with body. The device materials should not-either directly or though the release of their material constituents-produce any local or systemic adverse effects, be carcinogenic, or produce adverse reproductive and/or development effects. Within the ambit of medical devices, biomedical implants require special considerations of safety and accuracy. From dental fillings to pacemakers, most implants remain in vivo for the entire duration of a patient's life. This obligates stake holders including manufacturers, suppliers, healthcare professionals and patients to attach highest degree of caution in dealing with medical and surgical implants. Nation's infrastructure and process capabilities towards testing of implants are of paramount importance.

Table 1: Represents the various standard tests used for biomedical testing of implants

\begin{tabular}{c|c}
\hline Sr No. & Standard test \\
\hline 1. & Corrosion test and particle test \\
2. & Wear and tear test \\
3. & $\begin{array}{c}\text { Fluid flow test to determine functionality of } \\
\text { device in the presence of body fluids } \\
\text { Spine stimulator testing (for orthopaedic } \\
\text { implants) }\end{array}$ \\
5. & Total knee wear testing (for orthopaedic \\
implants)
\end{tabular}

\section{Commonly used composite materials for biomedical implants}

Materials for the biomedical implants should be [45-48] biocompatible, mechanically strong, and corrosion resistant. More specifically, biocompatibility refers the materials ability to provide a suitable host response in a specific application. The commonly used composite materials for biomedical applications are exhibited in Fig. 3.

Moreover, there exist a significance differences in relation to the HA coating microstructure, when deposited by HVOF and plasma techniques. Figure 4 summarizes the different coating microstructure deposited by HVOF and plasma spray by means of the SEM images. HVOF process has different microstructure than plasma spraying as exhibited in Fig. 4 (a \& b). Due to lower flame temperature of HVOF process HA grains doesn't melt completely in comparison with plasma method. HA coatings deposited by plasma method has lower amount of un-melted particles and microstructure consists of good flat lamellae. Furthermore, the reported average diameter of splats in case of plasma spray is higher in comparison to the HVOF [49].

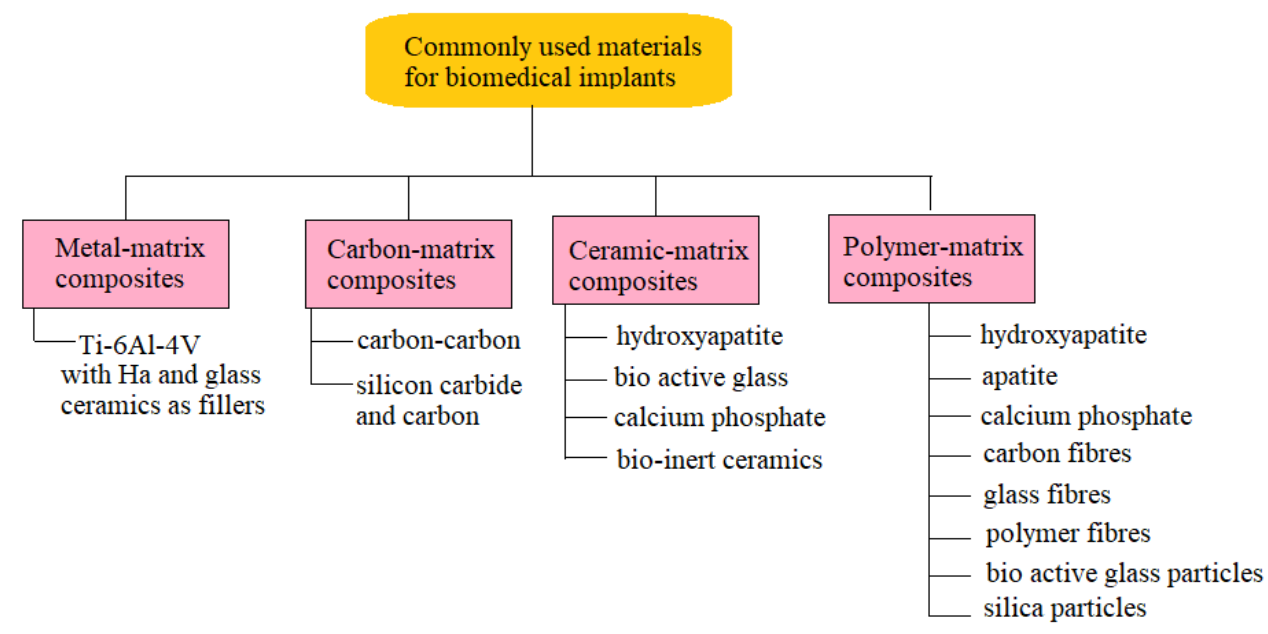

Figure 3: Commonly used composite materials for biomedical applications 


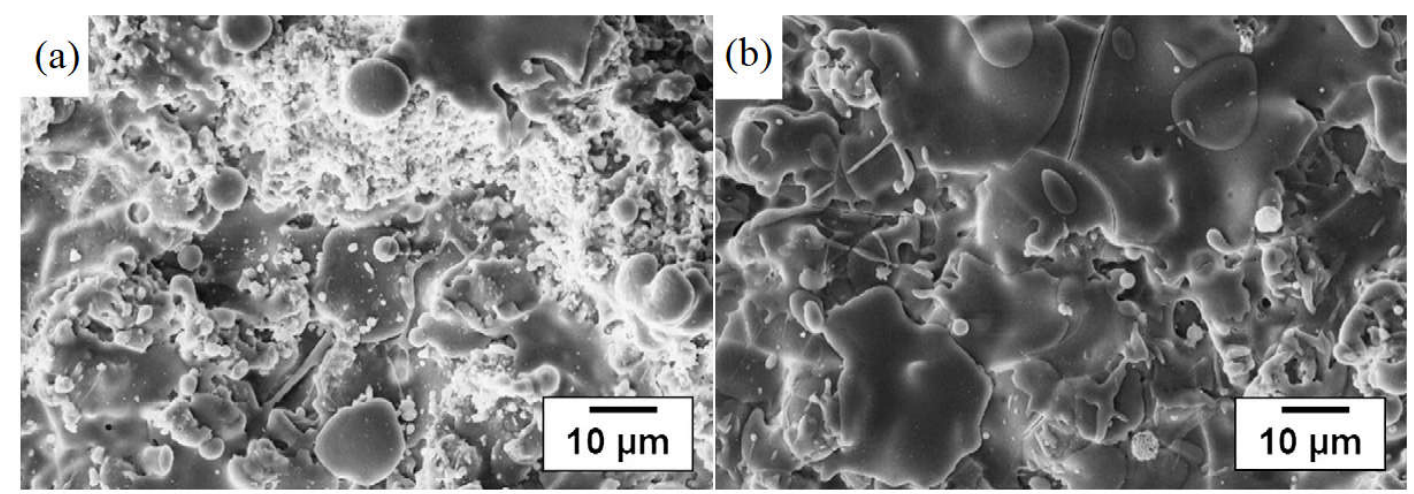

Figure 4: Cross-sectional views of (a) HVOF coating, and (b) Plasma sprayed coating [49]

\section{Conclusions}

Biomaterials surface modification has become an important topic, especially to overcome the rejection reactions, like inflammation and allergic. During surgery when biomaterials are implanted into the patient's body then most of the biomaterials will interact/or react with host environment, owning to which required effect cannot be achieved. Thus, surface modification of these is the best method to enhance its different properties. Designer biomaterials like composites consisting of bioactive bioceramic-polymer are specially fabricated materials according to the requirements needed for clinical situations and are utilized to solve different medical problems. This chapter discusses various thermal spraying techniques used for deposition of composite coatings for biomedical implants.

These surface modification techniques are of great use to assist the practical application of implants; however, still there are some limitations. In order to enhance the success rate of biomedical implants and to achieve long-duration stability of biomedical implants, it is must to fabricate composite coatings. As discussed in this article research carried out by groups/professionals can;

a) promote and enhance formation of bone tissues on metallic implants; and

b) protect metallic implants against corrosion in the patient body environment and restricting (or reducing) release of the cytotoxic ions from the metal implants to nearby tissue, and

c) heat treatment (HT) of HA composite coatings also yield positive results.

Composite coatings required to be designed carefully, with special focus onto the material of coating and fabrication method opted for formulation of coating. The choice of a specific surface modification method for depositing the coatings relies on various factors. In future new and advanced practical methods, especially methods in the area of nanotechnology, will develop and can be employed for the modification purpose.

\section{References}

1. Kurtz S., Mowat F., Ong K. Prevalence of primary and revision total hip and knee arthroplasty in the United States from 1990 through 2002. J. Bone Jt. Surg. Am. 2007; 89: 780-785.

2. Barrere F., Mahmood T., De Groot K., Van Blitterswijk C. Advanced biomaterials for skeletal tissue regeneration: Instructive and smart functions. Mater. Sci. Eng. R Rep. 2008; 59: 38-71.

3. Zethraeus N., Borgström F., Ström O. Cost-effectiveness of the treatment and prevention of osteoporosis-A review of the literature and a reference model. Osteoporos. Int. 2007; 18: 9-23.

4. Black J., Hastings G. (eds.) Handbook of biomaterial properties. Chapman \& Hall, London; 1998.

5. Ratner BD., Hoffman AS., Schoen FJ., Lemons J. (Eds.) Biomaterials science: an introduction to materials in medicine, 2nd Edn., Academic Press, San Diego; 2004.

6. Brunette DM., Tengvall P., Textor M., Thomsen P. Titanium in medicine: material science, surface science, engineering, biological responses and medical applications. Springer, Berlin; 2001.

7. Yahia L. (ed.) (2000) Shape memory implants. Springer, Berlin; 2000.

8. Plant SD., Grant DM., Leach L. Behaviour of human endothelial cells on surface modified NiTi alloy. Biomaterials. 2005;26: 5359-5367.

9. Winter GD., Gibbons DF., Plenk JR. H. (Eds.) Biomaterials 1980. John Wiley \& Sons, Chichester; 1982.

10.Oonishi H., Aoki H., Sawai K. (Eds.) Bioceramics. 1: Ishiyaku EuroAmerica, Tokyo; 1989.

11.Prado M., Zzavaglia C. (Eds.) Bioceramics. 2009; 21: Trans Tech Publications, Switzerland.

12.DE groot K. Bioceramics of calcium phosphate. CRC Press, Boca Raton; 1983.

13.Yamamuro T., Hench LL., Wilson J. (Eds.) Handbook of bioactive ceramics. Vol.1 \& Vol.2, CRC Press, Boca Raton; 1990.

14.Hench LL., Wilson J. (Eds.) An introduction to bioceramics. World Scientific, Singapore; 1993.

15.Bonfield W, Grynpas MD, Tully AE, Bowman J, Abram J, (1981), 'Hydroxyapatite reinforced polyethylene - a mechanically compatible implant material for bone replacement', Biomaterials, 2, 185-186.

16.Prashar G., Vasudev H. Application of thermal spraying techniques used for the surface protection of boiler tubes in power plants: Thermal spraying to combat hot corrosion. IGI global. 2020; 112-134: doi: 10.4018/978-1-7998-48707.ch005

17.Totemeier TC., Wright RN., Swank WD. Mechanical and physical properties of high-velocity oxy-fuel sprayed iron aluminide coatings. Metallurgical and Materials Transactions. 2003; 34A: 2223-2231.

18.Totemeier TC., Wright RN., Swank WD. Microstructure and stresses in HVOF sprayed iron aluminide coatings. Journal of Thermal Spray Technology. 2002; 11: 400-408.

19.Henao J., Cruz-bautista M., Hincapie-Bedoya J., OrtegaBautista B., Corona-Castuera J., Giraldo-Betancur AL., Poblano-Salas CA. HVOF hydroxyapatite/titania-graded coatings: microstructural, mechanical, and in vitro characterization. Journal of Thermal Spray Technology. 2018; 27(8):1302-1321.

20. Li H., Ng BS., Khor KA., Cheang P., Clyne TW. Raman spectroscopy determination of phases within thermal sprayed hydroxyapatite splats and subsequent in vitro dissolution examination. Acta Materialia. 2004; 52(2): 445453.

21.Melero HC., Sakai RT., Vignatti CA., Benedetti AV., Fernández 
J., Guilemany JM., Suegama PH. Corrosion resistance evaluation of HVOF produced hydroxyapatite and TiO2hydroxyapatite coatings in Hanks' solution. Materials Research. 2018; 21(2):

22. Bolelli G., Bellucci D., Cannillo V., Lusvarghi L., Sola A., Stiegler N., De Nardo L., Müller P., Killinger A., Gadow R., Altomare L., Nardo LD. Suspension thermal spraying of hydroxyapatite: Microstructure and in vitro behaviour. Materials Science and Engineering. 2014; C34: 287-303.

23. Henao J., Salas CAP., Vargas F., Giraldo-Betancur AL., CoronaCastuera J., Mazón. Principle and applications of thermal spray coatings, IGI Global. 2020; 31-70. DOI: 10.4018/978-17998-4870-7.ch002

24.Zhu YC., Yukimura K., Ding CX., Zhang PY. Thin Solid Films, 2001; 388: 277.

25.Berndt CC. (Ed.) Thermal spray processing of nanoscale materials II - extended abstracts. J. Therm. Spray Technol. 2001;10: 147 .

26.Webster TJ., Siegel RW., Bizios R. Biomaterials. 20: 1221.

27.Gaona M., Lima RS., Marple BR. Nanostructured titania/hydroxyapatite composite coatings deposited by high velocity oxy-fuel (HVOF) spraying. Materials Science and Engineering. 2007; A 458: 141-149.

28.Li H., Khor KA., Kumar R., Cheang P. Characterization of hydroxyapatite nano-zirconia composite coatings deposited by high velocity oxy-fuel (HVOF) spray process. Surface and Coatings Technology. 2004; 182: 227-236.

29. Henao J., Cruz-bautista M., Hincapie-Bedoya J., OrtegaBautista B., Corona-Castuera J., Giraldo-Betancur AL., Espinosa-Arbelaez DG., Alvarado-Orozco JM., Clavijo-Mejı́a GA., Trapaga-Martı́nez LG., Poblano-Salas CA. HVOF Hydroxyapatite/Titania-Graded Coatings: Microstructural, Mechanical, and In Vitro Characterization. J Therm Spray Tech.

30.DE Groot K., Geesink RGT., Klein CPAT., Serekian P. Plasma sprayed coatings of hydroxyapatite. Journal of Biomedical Materials Research. 1987; 21: 1375-1387.

31. Lacefield WR. Hydroxylapatite coatings', in An introduction to bioceramics, Edited by LL Hench and I Wilson, World Scientific, Singapore; 1993

32.Pawlowski L. The science and engineering of thermal spray coatings, $2^{\text {nd }}$ Edn., John Wiley \& Sons, Chichester; 2008.

33. Heimann RB. Plasma-spray coatings: principles and applications. VCH, Weinheim;1996.

34. Balani K., Anderson R., Laha T. Plasma-sprayed carbon nanotube reinforced hydroxyapatite coatings and their interaction with human osteoblasts in vitro. Biomaterials. 2007; 28: 618-624.

35.Shamray V., Sirotinkin V., Smirnov I., Kalita V., Fedotov A. Barinov S., Komlev V., Fedotov A., Komlev V. Structure of the hydroxyapatite plasma-sprayed coatings deposited on preheated titanium substrates. Ceram. Int. 2017; 43: 9105-9109.

36.Sathish S., Geetha M., Aruna S., Balaji N., Rajam K., Asokamani R. Studies on plasma sprayed bi-layered ceramic coating on bio-medical Ti-13Nb-13Zr alloy. Ceram. Int. 2011; 37: 13331339.

37.Sathish S., Geetha M., Aruna S., Balaji N., Rajam K., Asokamani R. Sliding wear behavior of plasma sprayed nanoceramic coatings for biomedical applications. Wear. 2011; 271: 934941.

38. Kumari R., Majumdar JD. Wear Behavior of plasma spray deposited and post heat-treated hydroxyapatite (HA)-based composite coating on titanium alloy (Ti-6Al-4V) substrate. Metall. Mater. Trans. 2018; A 49: 3122-3132.

39. Hung KY., Lo SC., Shih CS., Yang YC., Feng HP., Lin YC Titanium surface modified by hydroxyapatite coating for dental implants. Surf. Coat. Technol. 2013; 231: 337-345.

40. Yang YC., Yang CY. Mechanical and histological evaluation of a plasma sprayed hydroxyapatite coating on a titanium bond coat. Ceram. Int. 2013; 39: 6509-6516.

41. Rahman ZU., Shabib I., Haider W. Surface characterization and cytotoxicity analysis of plasma sprayed coatings on titanium alloys. Mater. Sci. Eng. 2016; C 67: 675-683.

42. Ebrahimi N., Hossein ZASA., Vaezi MR. A new double-layer hydroxyapatite/alumina-silica coated titanium implants using plasma spray technique. Surf. Coat. Technol. 2018; 352: 474-482.

43.Cao L., Ullah I., Li N., Niu S., Sun R. Plasma spray of biofunctional (Mg, Sr)-substituted hydroxyapatite coatings for titanium alloy implants. J. Mater. Sci. Technol. 2018; 35: 719-726.

44.Ke D., Vu AA., Bandyopadhyay A., Bose S. Compositionally graded doped hydroxyapatite coating on titanium using laser and plasma spray deposition for bone implants. Acta Biomater. 2019; 84: 414-423.

45.Lutton PP., Ben-Nissan B. Mater. Tech. 1997;12(2):59-63.

46. Hofmann GO. Clinical Mater. 1992;10(1-2):75-80.

47.Tailor S., Vashishtha N., Modi A., Modi SC. Thermally Sprayed Porous PEEK Coating for Biomedical Implants. Journal of Thermal Spray and Engineering. 2019; 1(1): 32-36.

48.Tailor S., Vashishtha N., Modi A., Modi SC. One-step fabrication of thermal sprayed polymer coating on metals. Material research express. 2020; 7: 016425.

49.R. Gadow R., Killinger A., Stiegler N. Hydroxyapatite coatings for biomedical applications deposited by different thermal spray techniques. Surface \& Coatings Technology. 2010; 205: 1157-1164. 